\title{
Inhibitory effect of a formulated extract from multiple citrus peels on LPS-induced inflammation in RAW 246.7 macrophages
}

\author{
Tadahiro Etoh', Yong Pil Kim¹, Masahiko Hayashi', Michiko Suzawa², Shiming \\ $\mathrm{Li}^{3}$, Chi-Tang $\mathrm{Ho}^{3}$, and Kanki Komiyama ${ }^{4}$
}

${ }^{1}$ Faculty of Pharmacy, Iwaki Meisei University, Iino, Chuo-dai, Iwaki, Fukushima 970-8551, Japan; ${ }^{2}$ Miyauchi Citrus Research Center, Shigoka-Machi, Takasaki, Gunma, 370-0845,Japan ${ }^{3}$ Department of Food Science, Rutgers University, New Brunswick, NJ 08901, USA; ${ }^{4}$ Kitasato Research Center for Environmental Sciences, Kitasato, Sagamihara, Kanagawa, 252-0329, Japan

Corresponding author: Kanki Komiyama, Kitasato Research Center for Environmental Sciences, Kitasato, Sagamihara, Kanagawa, 252-0329, Japan

Submission date: April 28, 2013; Acceptance date: June 20, 2013; Publication date: June 26, 2013

\section{ABSTRACT:}

Background: Formulated Citrus Peel Extract (GL) made from the peels of six citrus fruits available in Japan, namely navel oranges, citrus hassaku, citrus limon, citrus natsudaidai, citrus miyauchi and satsuma, was initially developed as a cosmetic product to protect skin from UV irradiation. Anecdotal evidences of anti-cancer property of GL have been reported by consumers based on the cases such as topical application for melanoma, and oral ingestion for prostate, lung and liver cancers.

Those anecdotal reports stimulated us to investigate anti-tumorigenesis activity of GL. In the previous study, we reported that the topical application of GL inhibited DMBA/TPA-induced skin tumor formation by decreasing inflammatory gene parameters.

Objective: In this study, we mainly investigated the effect of GL on translocation of NF-kB together with production of nitric-oxide and TNF- $\alpha$ induced by LPS in RAW 264.7 cells. 
Results: This investigation showed that GL decreased the release of TNF- $\alpha$ and nitric oxide from macrophage RAW264.7 cells stimulated by LPS in a dose-dependent manner. In addition, GL suppressed the expression of iNOS and nuclear translocation of NF-kB in RAW264.7 cells, inhibited the degradation of IкB- $\alpha$, and scavenged hydroxyl radicals (DMPO/OH adduct) in vitro.

Conclusions: Our findings suggest that GL suppresses the inflammation in vitro, and exerts chemopreventive activity through the inhibition of production of TNF- $\alpha$ and iNOS proteins due to the inhibition of nuclear translocation of NF-kB and oxidative stress. GL appears to be a novel functional natural product capable of preventing inflammation and inflammation-associated tumorigenesis.

Keywords: GL, Citrus peel extract, anti-inflammation, Nitric oxide, iNOS, NF-kB, TNF- $\alpha$

\section{INTRODUCTION:}

Citrus peel has been used traditionally as peptic and bronchial agent in oriental medicine and recently this has been reported to exhibit a broad spectrum of biological activity such as anti-inflammation, suppression of tumorigenesis in experimental animals [1,2]. The citrus peel is a rich source of flavonoids, as well as many polymethoxylated flavones, which are very rare in other plants [3]. These compounds not only play important roles in biological activities but also in commercial applications in the food and pharmaceutical industries [4].

Mounting evidence suggests that chronic inflammation mediates most chronic diseases, including cancer. Among other transcription factors, nuclear factor-kappaB (NF- $\kappa \mathrm{B})$ has emerged as major regulators of inflammation, cellular transformation, tumor cell survival, proliferation, invasion, angiogenesis and metastasis [5]. Thus, agents that can inhibit NF- $\kappa \mathrm{B}$ activation pathways have a potential for both prevention and treatment of cancer [6].

Formulated Citrus Peel Extract (GL) is made from the peels of six citrus fruits available in Japan, namely navel oranges, citrus hassaku, citrus limon, citrus natsudaidai, citrus miyauchi and Satsuma. It was initially developed as a cosmetic product to protect skin from UV irradiation. Anecdotal evidences of anti-cancer property of GL have been reported by consumers based on the cases such as topical application for melanoma, and oral ingestion for prostate, lung and liver cancers. These anecdotal reports stimulated us to investigate anti-inflammation and anti-tumorigenesis activities of GL in animal models.

We previously demonstrated that oral feeding of GL suppressed colonic tumorigenesis 
induced by azoxymethane [7]. In addition, GL also inhibited DMBA/TPA-induced skin tumor formation [8]. In this study, we investigated the effect of GL on translocation of $\mathrm{NF}-\kappa \mathrm{B}$ together with production of nitric-oxide and TNF- $\alpha$ induced by LPS in vitro.

\section{MATERIALS AND METHODS:}

Citrus Peel Extract: Commercially available formulated citrus peel extract (GL, Miyauchi Citrus Research Center, Gunma, Japan) made from the peels of six citrus fruits was used in this study.

Reagents: Polyclonal antibodies specific for I $\kappa \mathrm{B}-\alpha, \mathrm{NF}-\kappa \mathrm{B}$ and anti-rabbit IgG, HRP-linked antibody were purchased from Cell Signaling Technology (MA, U.S.A.). Biotinylated anti-mouse, goat $\operatorname{IgG}(\mathrm{H}+\mathrm{L})$ and Vectastain $\mathrm{ABC}$ kit were purchased form Vector Laboratories (CA, U.S.A.). The ECL western blot detection reagent was purchased from GE Healthcare (NJ, U.S.A.). Dulbecco's Modified Eagle's Medium (DMEM) and lipopolysaccharides (LPS, form Escherichia coli, serotype 026:B6) and protease inhibitor cocktail were obtained from Sigma-Aldrich (MO, U.S.A.). Tumor necrosis Factor alpha (TNF- $\alpha$ ) ELISA kit was purchased from Pierce Biotechnology (IL, U.S.A.).

Cell culture: RAW264.7 cells, a murine macrophage-like cell line, were obtained from Riken Cell Bank (Tsukuba, Ibaraki, Japan). Cells cultured in phenol red-free DMEM, supplemented with $10 \%$ fetal bovine serum (FBS) (EIDIA, Tokyo, Japan), $100 \mathrm{U} / \mathrm{mL}$ penicillin (Meiji seika, Tokyo, Japan), $100 \mu \mathrm{g} / \mathrm{mL}$ streptomycin (Meiji seika, Tokyo, Japan) and 2mM L-glutamine (Life Technologies Co., NY, U.S.A.). All experiments were performed with cells grown to $80-90 \%$ confluence and following no more than 15 passages.

Measurement of cell viability: Cell viability was assessed by MTT assay. RAW264.7 cells plated in 96 well tissue culture dishes $\left(1 \times 10^{5}\right.$ cells $)$ were treated with various concentrations of GL $(1,3,10 \%)$ for 20 hours. Then MTT (Sigma) was added $(0.5 \mathrm{mg} / \mathrm{mL})$ and incubated for 4 hours. The culture medium was removed, and cells were dissolved in dimethyl sulfoxide (Wako). The optical densities (OD) at $540 \mathrm{~nm}$ and $620 \mathrm{~nm}$ were measured using a microplate reader (Model 680, Bio-Rad Laboratories, CA, U.S.A.).

Measurement of NO: Nitrite concentrations in the conditioned medium were determined by using Griess reagent (1\% sulfanilamide (Sigma), $0.1 \% \quad N$-1-naphthylenediamine dihydrochloride (Sigma), and 2.5\% phosphoric acid (Kanto chemical, Tokyo, Japan)) (Green 
LC et al., 1982). RAW264.7 cells $\left(1 \times 10^{5}\right.$ cells/well) were preincubated at $37^{\circ} \mathrm{C}$ for 3 hours with or without various concentrations of GL (1, 3, 10\%). After pre-incubation, LPS (10 $\mu \mathrm{g} / \mathrm{mL}$ ) was added, and cells were incubated for 20 hours. After incubation, $100 \mu \mathrm{L}$ aliquots of medium were mixed with an equal volume of Griess reagent. Absorbance was measured at $540 \mathrm{~nm}$ with a microplate reader after incubating for 5 minutes.

Measurement of TNF- $\alpha$ : RAW264.7 cells $\left(1 \times 10^{5}\right.$ cells/well) were preincubated at $37^{\circ} \mathrm{C}$ for 3 hours with or without various concentrations of GL (1, 3, 10\%). After incubation, LPS (10 $\mu \mathrm{g} / \mathrm{mL}$ ) was added, and cells were incubated for 6 hours. After incubation, the culture media in a 96-well plate were harvested, centrifuged at $370 \times g$ for 10 minutes at $4^{\circ} \mathrm{C}$, and the supernatant removed and frozen at $-30^{\circ} \mathrm{C}$ until assay. TNF- $\alpha$ concentration in the supernatants was measured by ELISA.

Western blot analysis: RAW264.7 cells were plated at $2 \times 10^{6}$ cells/well in 6 well plates and preincubated at $37^{\circ} \mathrm{C}$ for 3 hours with various concentrations of GL. Cells were then treated with LPS $(10 \mu \mathrm{g} / \mathrm{mL})$ for the times indicated in the text. The cells were washed in cold PBS and lysed in $75 \mu \mathrm{L}$ lysis buffer (20 mM HEPES pH 7.3) supplemented with $1 \%$ Triton-X, $10 \%$ glycerol, $1 \mathrm{mM}$ sodium fluoride, $1 \mathrm{mM} \mathrm{Na}_{3} \mathrm{VO}_{4}$ and protease inhibitor cocktail. After 15 minutes incubation on ice, cells were collected in sample tube by silicon policeman and incubated at 10 minutes on ice. Then cells were centrifuged at $15490 \times g$ for 20 minutes at $4^{\circ} \mathrm{C}$. The supernatant fractions were boiled for 5 minutes in sample buffer $(50 \mathrm{mM}$ Tris, pH7.4, 4\% SDS, $10 \%$ glycerol, 4\% 2-mercaptoethanol and $50 \mu \mathrm{g} / \mathrm{mL}$ bromophenol blue). Preparation of nuclear extracts was performed, as follows. RAW264.7 cells $\left(2 \times 10^{7}\right.$ cells/well) were plated in $10 \mathrm{~cm}$ tissue culture dishes. The cells were pre-incubated at $37^{\circ} \mathrm{C}$ for 3 hours with or without various concentration of GL and treated with LPS for each time. At the end of incubation, the cells were harvested by scraping, followed by centrifugation at $210 \times g$ and $4^{\circ} \mathrm{C}$ for 5 minutes. After centrifugation, the cell pellet was resuspended in $800 \mu \mathrm{L}$ of Tris-buffered $\mathrm{KCl}$ solution (20 mM Tris- $\mathrm{HCl}, \mathrm{pH} 7.8,50 \mathrm{mM} \mathrm{KCl}$ ) supplemented with $1 \mathrm{mM}$ dithiothreitol, $50 \mathrm{mM}$ sodium fluoride, $1 \mathrm{mM} \mathrm{Na} \mathrm{VO}_{4}$ and protease inhibitor cocktail. Nonidet P-40 substitute (Wako) was added at $0.6 \%$ final concentration, and the cell suspension was vortexed for 10 seconds and centrifuged at $15490 \times \mathrm{g}$ for 1 minute at $4^{\circ} \mathrm{C}$ to obtain the nuclei pellet. The nuclei were resuspended in $30 \mu \mathrm{l}$ ice-cold Tris-buffered high-KCl solution (20 mM Tris- $\mathrm{HCl}, \mathrm{pH} 7.8,500 \mathrm{mM} \mathrm{KCl}$ ) supplemented with $20 \%$ glycerol, $1 \mathrm{mM}$ dithiothreitol, $50 \mathrm{mM}$ sodium fluoride, $1 \mathrm{mM} \mathrm{Na}_{3} \mathrm{VO}_{4}$ and protease inhibitor cocktail. After 1 hour incubation on ice, the nuclear lysate was centrifuged at $15490 \times g$ for 20 minutes at $4^{\circ} \mathrm{C}$, 
and the supernatant (nuclear extract) was mixed with $3 \times$ SDS/PAGE sample buffer $(50 \mathrm{mM}$ Tris, pH 7.4, 4\% SDS, $10 \%$ glycerol, 4\% 2-mercaptoethanol and $0.05 \mathrm{mg} / \mathrm{mL}$ bromophenol blue) at 2:1 ratio, boiled for 5 minutes, and stored at $-80^{\circ} \mathrm{C}$. The proteins were separated by 8\% SDS-PAGE and transferred to a PVDF membrane in transfer buffer (20 mM Tris, $\mathrm{pH} 8.3$, $150 \mathrm{mM}$ glycine, 20\% methanol). The PVDF membrane was then blocked by incubation in 20\% Block ace (DS Pharma Biomedical., Osaka, Japan). Subsequently, the membrane was incubated with the each antibody for overnight at $4{ }^{\circ} \mathrm{C}$ and finally incubated for 4 hours at $4^{\circ} \mathrm{C}$ with a secondary antibody. The protein bands were visualized using an enhanced chemiluminescence system (Amersham Biosciences, NJ, U.S.A.).

Radical scavenging activity: Inhibition of iron-induced hydroxyl radical formation was determined using the electron spin resonance (ESR) trapping technique in combination with DMPO. The DMPO-OH adduct was obtained from the Fenton reaction system containing DMPO $(10 \mu \mathrm{L}), \mathrm{H}_{2} \mathrm{O}_{2}(0.1 \mathrm{mM}: 40 \mu \mathrm{L})$, and ferrous sulfate (5 mM: $\left.20 \mu \mathrm{L}\right)$ with or without GL $(5,10,20 \mu \mathrm{L})$. The mixture was transferred to a flat quartz cell, and the ESR spectrum was measured 4 minutes after the addition of ferrous sulfate. The spin adducts generated in the reaction system were detected using a JEOL RE2X ESR spectrometer (JEOL, Japan). Instrument conditions were as follows: central magnetic field $336 \mathrm{mT}$ (328.5-343.5 mT), $9.425 \mathrm{GHz}$, microwave power of $1.0 \mathrm{~mW}$, modulation frequency $100 \mathrm{kHz}$, response rate $0.1 \mathrm{~s}$, scanning time 4 minutes, room temperature $\left(23^{\circ} \mathrm{C}\right)$.

Statistical analysis: The data were expressed as a mean \pm SEM of the results obtained from a number of experiments. The statistical significance of the results was analyzed by Student's t-test.

\section{RESULTS:}

Effect of GL on cell viability of RAW 264.7 cells: To examine cytotoxicity of GL on RAW 264.7 cells, cells were exposed to various concentrations of GL $(1,3,10 \%)$ for 20 hours, and cytotoxicity was monitored using the MTT assay. GL had no influence on cell viability of RAW 264.7 cells (Fig. 1). 


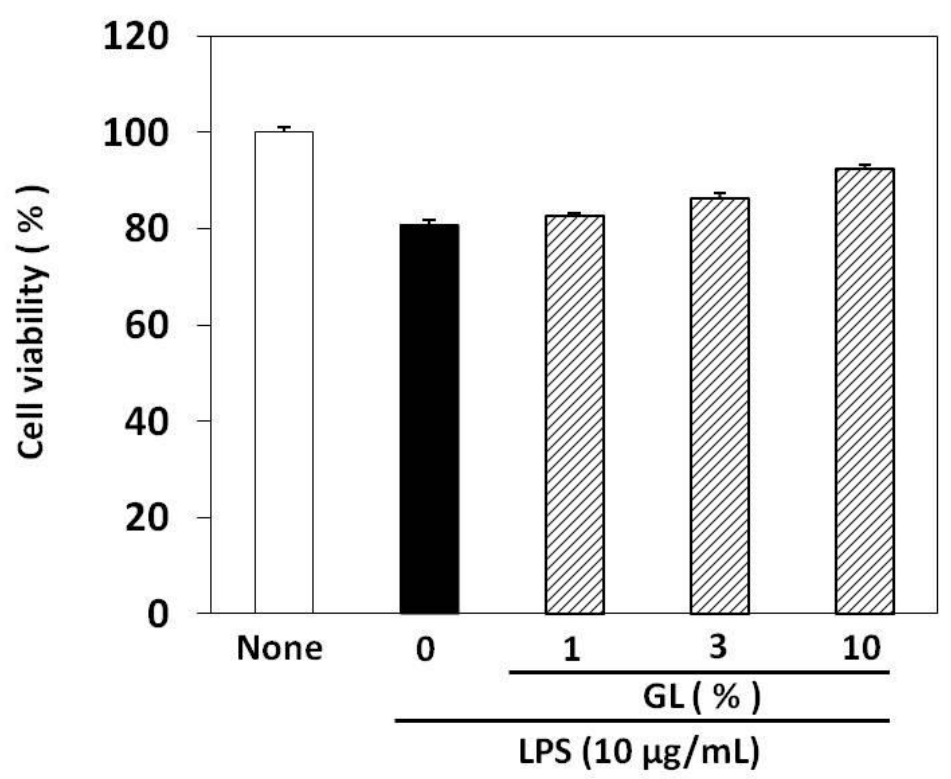

Figure 1. Effect of GL on cell viability of RAW 264.7 cells. RAW264.7 cells (1.0 X $10^{5}$ cells/well) were pretreated at $37^{\circ} \mathrm{C}$ for $3 \mathrm{~h}$ with various concentration of GL $(1,3,10 \%)$ before LPS $(10 \mu \mathrm{g} / \mathrm{ml})$ was added, and cells were incubated for $20 \mathrm{~h}$. After incubation, the cell viability were measured by MTT assay. The cell viability was defined as the $\%$ of non-stimulated cells. Result shown are representatives of three independent experiments.

Effect of GL on NO and TNF-a production: Incubation with LPS for 20 hours increases the production of nitrite and TNF- $\alpha$ in RAW 264.7 cells. GL reduced the production of nitrite and TNF- $\alpha$ in cell culture supernatants dose-dependently as shown in Fig. 2.
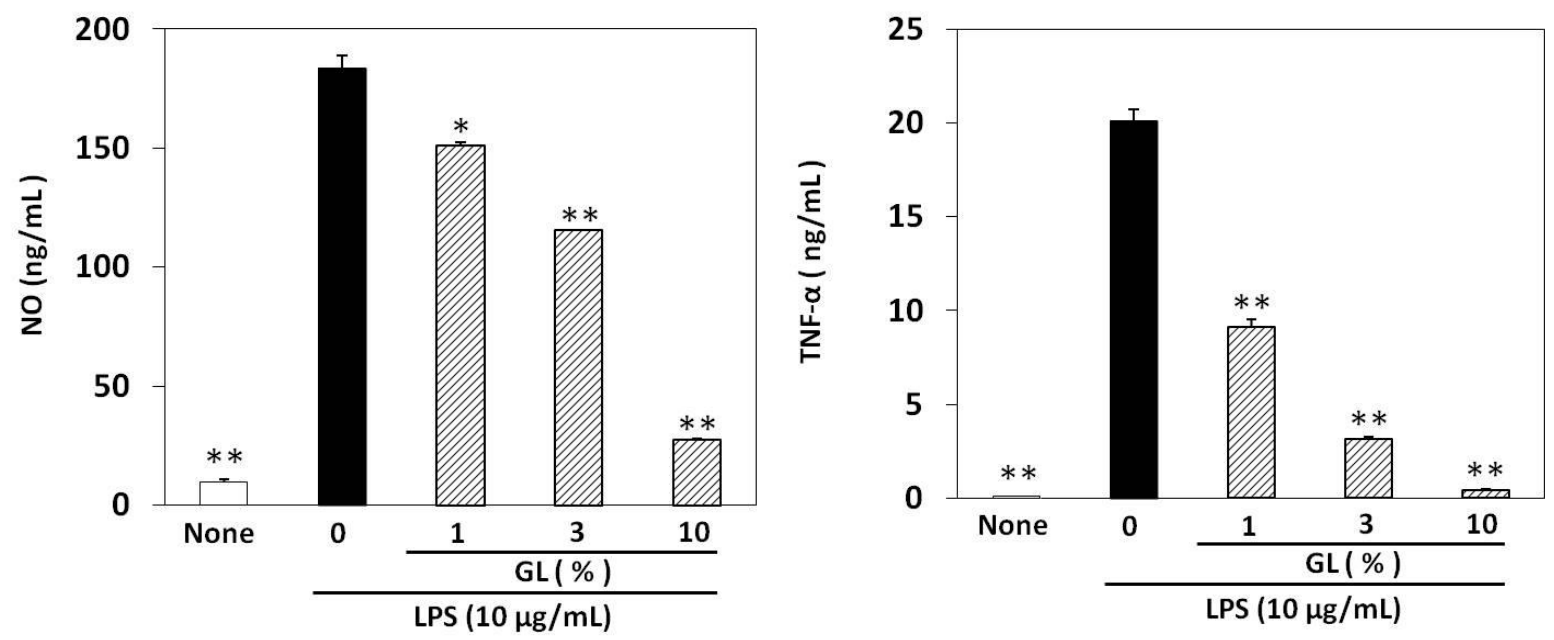

Figure 2. Effect of GL on NO and TNF- $\alpha$ production. RAW 264.5 cells $\left(1.0 \times 10^{5}\right.$ cells/well) were incubated in 96-well plates for 24 hours and GL was added at final concentrations of 1, 3, and $10 \%$ and incubated for 3 hours. After the treatment, LPS $(10 \mathrm{mg} / \mathrm{mL})$ was added and incubated for further 20 hours, and the nitrite production was measured by Griess reaction. Statistical significance; ${ }^{*} \mathrm{P}<0.05,{ }^{*} * \mathrm{P}<0.01$ vs. corresponding LPS control. 
Effect of GL on iNOS protein expression: To assess whether the reduced production of nitrite in GL-treated RAW 264.7 cells is due to decease in iNOS protein level, immunoblotting experiments using a specific anti-iNOS antibody were performed. Cells were treated with GL for 3 hours, and stimulated with LPS for 20 hours. As shown in Fig. 3, GL strongly inhibited the expression of iNOS protein dose-dependently.
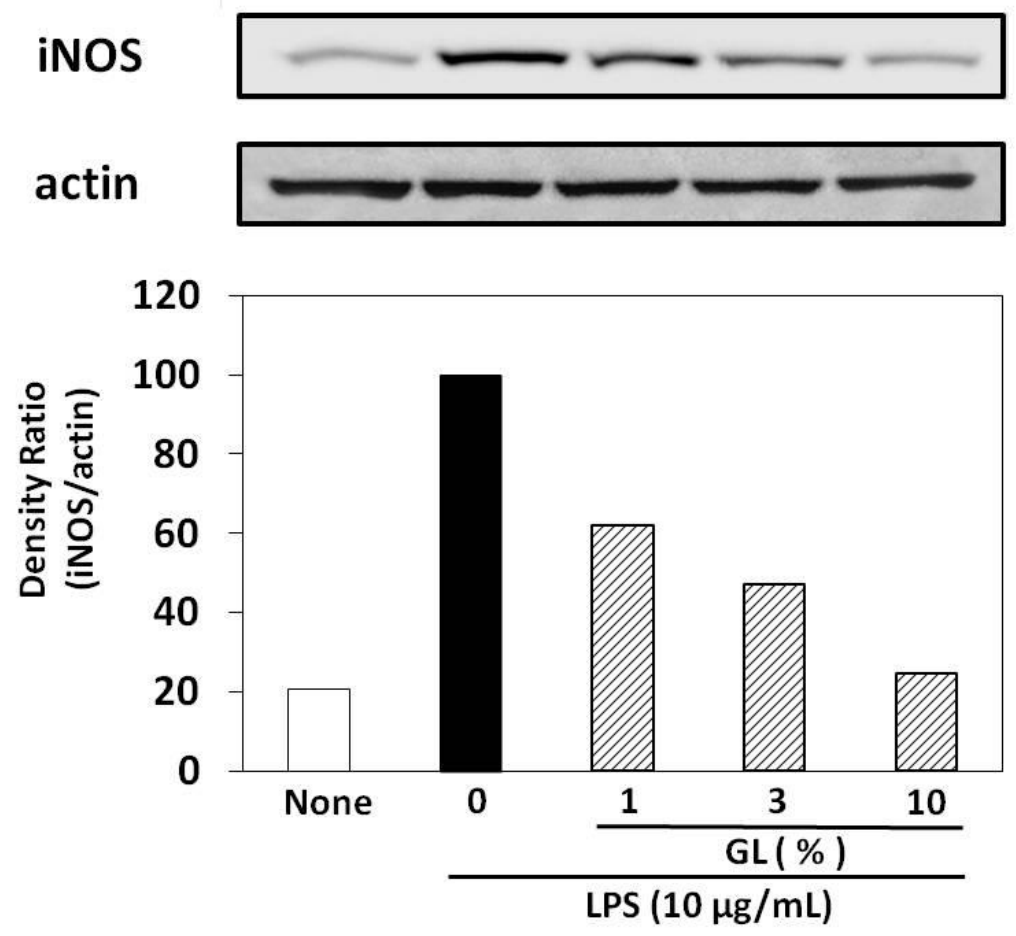

Figure 3. Effect of GL on iNOS protein expression. RAW 264.5 cells were treated with GL at final concentrations of 1,3 , and $10 \%$ and incubated for 3 hours. After the treatment, LPS $(10 \mu \mathrm{g} / \mathrm{mL})$ was added and incubated for further 20 hours, and the protein formation was measured by western blot analysis. To facilitate comparisons, the relative density ratios of iNOS protein to actin protein are shown as histogram. The density ratio of LPS control is set to 100. Result shown are representatives of three independent experiments.

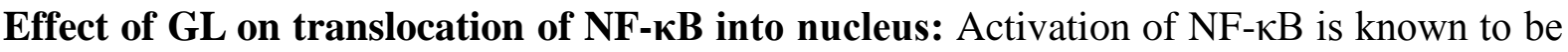
required for iNOS expression and TNF- $\alpha$ production. Therefore, we investigated the translocation of p65, a subunit of NF- $\mathrm{BB}$, from the cytosol to the nucleus by Western blot analysis. RAW264.7 cells were pretreated for 3 hours with $10 \%$ of GL before LPS was added. When RAW264.7 cells were incubated at $37{ }^{\circ} \mathrm{C}$ in medium containing LPS for 15 minutes, p65 protein levels were increased. It indicated that NF- $\kappa B$ translocated into nucleus when treated with LPS. In the presence of GL (10\%), translocation of NF- $\kappa$ B into nucleus was suppressed significantly. On the other hand, GL did not affect on the protein levels of Oct-1 which suggested it did not disturb normal physiological functions in nucleus (Fig. 4). 

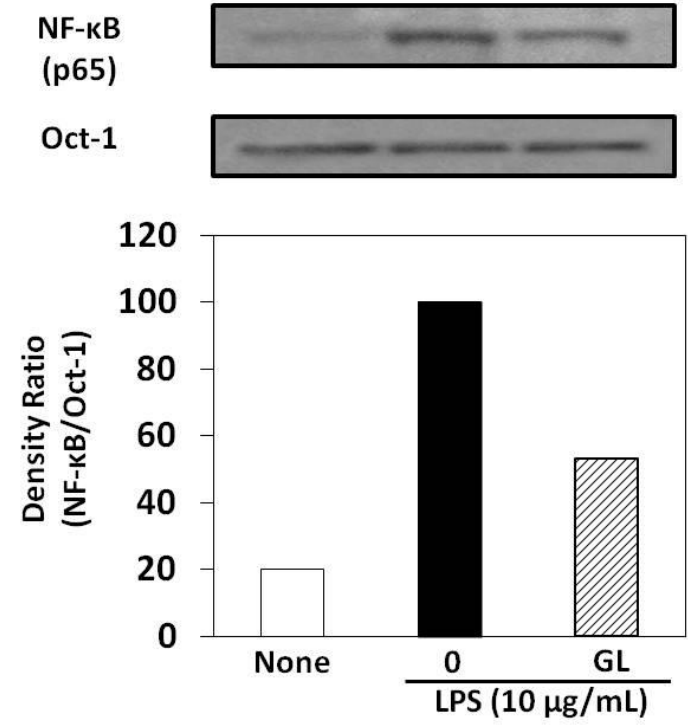

Figure 4. Effect of GL on translocation of NF- $\mathrm{BB}$ into nucleus. RAW264.7 cells were pretreated at $37{ }^{\circ} \mathrm{C}$ for 3 hours with $10 \% \mathrm{GL}$, LPS $(10 \mu \mathrm{g} / \mathrm{mL})$ was added, and cells were incubated for 15 minutes. After incubation, levels of NF-kB (p65) and Oct-1 protein in the nuclear extract samples were determined by Western blot. To facilitate comparisons, the relative density ratios of NF- $\mathrm{kB}$ protein to Oct-1 protein are shown as histogram. The density ratio of LPS control is set to 100. Results shown are representatives of three independent experiments.

Effect of GL on degradation of $\mathbf{I} \kappa \mathbf{B}-\boldsymbol{\alpha}$ : To determine whether GL inhibited degradation of I $\mathrm{B}-\alpha$, cell lysates of RAW264.7 treated with GL cells were prepared. RAW264.7 cells were pretreated with GL (10\%) for 3 hours and then incubated in the presence of LPS for various periods $\left(5,10,15,30,60\right.$ minutes). When RAW264.7 cells were incubated at $37{ }^{\circ} \mathrm{C}$ for 10 or 15 minutes in medium containing LPS, the I $\kappa \mathrm{B}-\alpha$ was degraded. However, when the cells were pretreated with GL (10\%), the IкB- $\alpha$ level did not change. Furthermore, GL (10\%) did not affect the actin level (Fig. 5).
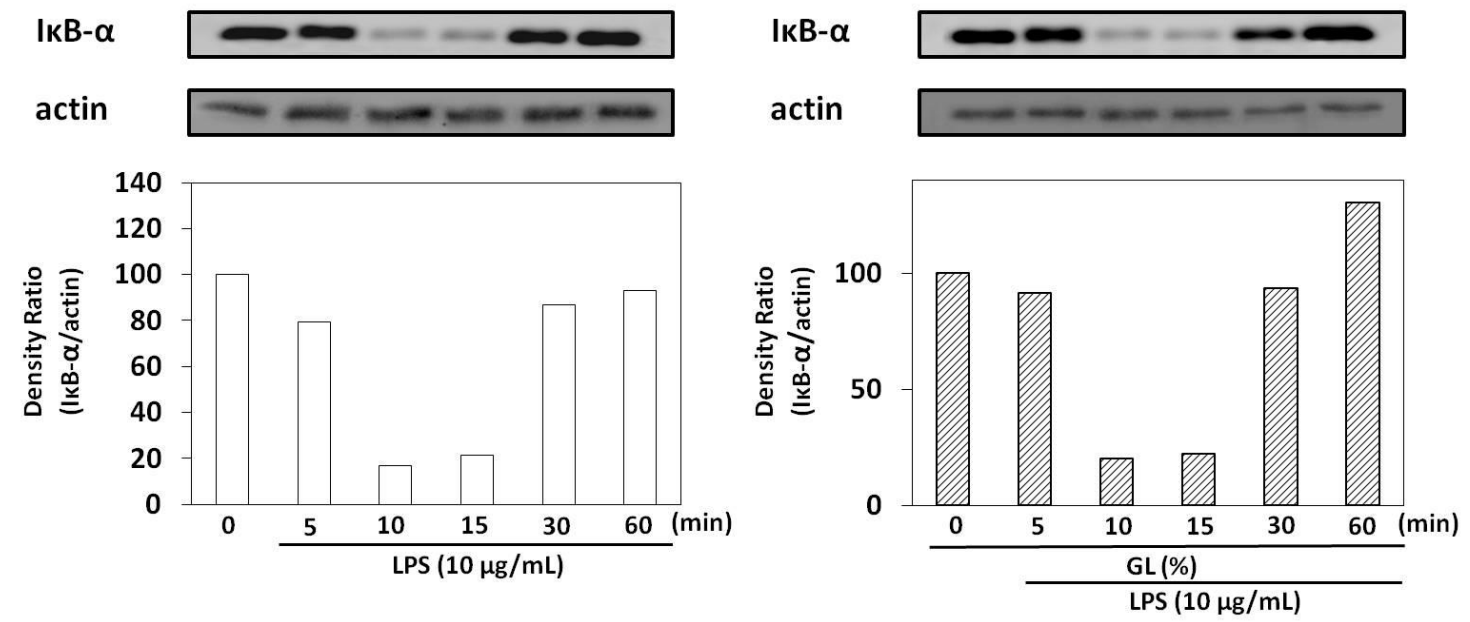

Figure 5. Effect of GL on degradation of IKB- $\alpha$. RAW264.7 cells $\left(2.0 \times 10^{6}\right.$ cells/well $)$ were incubated at $37{ }^{\circ} \mathrm{C}$ for 3 hours in $2 \mathrm{~mL}$ medium in the presence or absence of GL (10\%) before LPS $(10 \mu \mathrm{g} / \mathrm{mL})$ was 
added, and cells were incubated for indicated time $(0,5,10,15,30,60$ minutes). The protein levels of I $\kappa \mathrm{B}-\mathrm{a}$ and actin were determined by Western blot. To facilitate comparisons, the relative density ratios of IкB-a protein to actin protein are shown as histogram. The density ratio of non-stimulated control is set to 100 . Results shown are representatives of three independent experiments.

Radical scavenging effect of GL: The antioxidant activity of GL was evaluated by Fenton reaction system with the ESR spin-trapping technique. Figure 6 showed that GL at concentrations of $6.7 \%(\mathrm{~B}), 12.5 \%$ (C) and $22.2 \%$ (D) reduced the ESR signal intensity by $22 \%, 42 \%, 70 \%$ as compared with that of control (A), respectively.
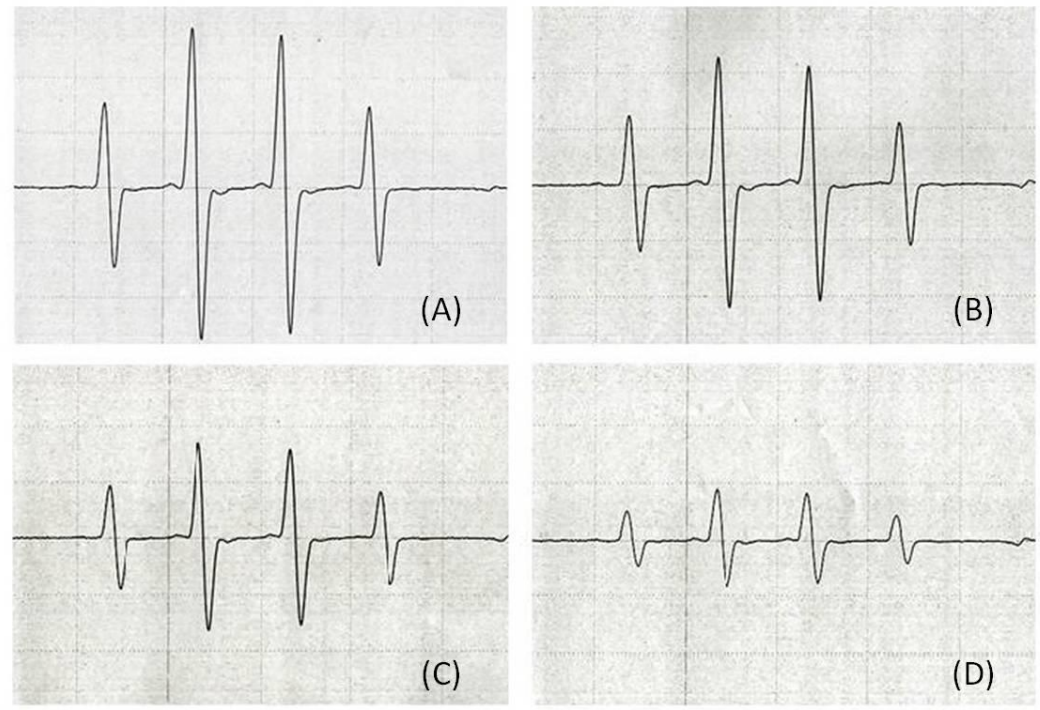

Figure 6. Radical scavenging effect of GL. The DMPO-OH adduct was obtained from the Fenton reaction system containing DMPO $(10 \mu \mathrm{L}), \mathrm{H}_{2} \mathrm{O}_{2}(0.1 \mathrm{mM}: 40 \mu \mathrm{L})$, and ferrous sulfate $(5 \mathrm{mM}: 20 \mu \mathrm{L})$ with or without GL $(5,10,20 \mu \mathrm{L})$. ESR spectra of DMPO adduct trapping hydroxyl radical (A) without, (B), (C), (D) with $6.7 \%, 12.5 \%$, and $22.2 \% \mathrm{GL}$, respectively.

\section{DISCUSSION:}

In this study, we evaluated the anti-inflammatory role of GL in RAW 264.7 cells and demonstrated that it attenuated LPS-induced inflammatory events by inhibiting iNOS

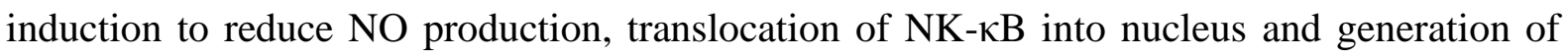
oxygen radicals.

Nitric oxide (NO) produced by the inducible forms of iNOS protein is an important cellular signaling molecule involved in many physiological processes [9]. However, excess production of NO plays an important role in various inflammatory conditions [10-13]. LPS was known to induce the expression of this enzyme which leads to the production of abundant amounts of NO. GL dose-dependently inhibited the production of NO caused by the inhibition on the expression of iNOS. 
Numerous evidences from preclinical and clinical studies have shown that NF- $\kappa \mathrm{B}$ and NF- $\mathrm{BB}$-mediated pro-inflammatory cytokines play a central role in the progression of inflammation and cancer-related symptoms. NF- $\kappa \mathrm{B}$ activity is induced by several factors including LPS and ROS. Activation of the NF- $\kappa \mathrm{B}$ is initiated by the degradation of $\mathrm{I} \kappa \mathrm{B}$, and then translocate into nucleus to leads to the given physiological response such as inflammatory response and cellular proliferation [14-17]. This study showed that GL

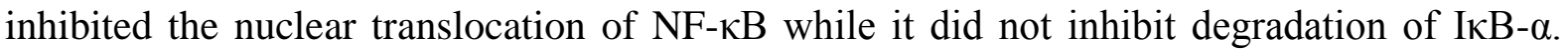
Therefore, it is considered that anti-inflammatory activity of GL was due to the inhibition on the translocation of NF- $\kappa \mathrm{B}$ into nucleus and consequently inhibiting the production of iNOS, TNF- $\alpha$ and oxygen radicals.

In the previous study, GL significantly inhibited TPA-induced mouse skin inflammation and DMBA/TPA-induced skin tumor formation and as the results the tumor incidence and tumor multiplicity of papillomas were reduced at 20 weeks [8]. We also reported that chemical analysis on GL revealed its richness of flavonoids including nobiletin, sinesetin, tangeretin, naringin and hesperidin with a total measured content as high as $464 \mathrm{ppm}$ or 0.46 $\mathrm{mg} / \mathrm{mL}[8]$. It is assumed that the biological activities of GL are due to synergistic effects among the rich flavonoids, particularly polymethoxyflavones in this formulated extract.

Although ROS such as OH-radicals can help the host defense systems, excessive ROS is capable of inducing DNA damaging and other bio-molecules. Increased formation of radicals can promote the development of malignancy, and the continuous generation of radicals may account for the increased risk of cancer development in the aged $[18,19]$. It can be inferred that chemo-preventive activity of GL on the skin tumor development is linked to the radical scavenger activity together with inhibition of NO and iNOS generation.

\section{CONCLUSION:}

In conclusion, GL inhibited iNOS induction in LPS-stimulated RAW 264.7 cells in a dose-dependent manner and reduced NO production by inhibition of iNOS activity, translocation of NF- $\mathrm{BB}$ into nucleus and radical scavenging activity. Therefore, these results indicate that GL serves as a valuable protective agent in inflammatory diseases as well as a preventing agent of tumor development.

Authors' Contributions: All authors contributed to this study.

Abbreviations:DMBA/TPA;7,12-dimethylbenz(a)anthracene/12-O-tetradecanoylphorbol-13 -acetate ROS; reactive oxygen species 
Acknowledgements and Funding: The authors would like to thank Prof. Nishimoto for the assistance of radical scavenger test.

\section{REFERENCES:}

1. Benavente-García O, Castillo J: Update on uses and properties of citrus flavonoids: new findings in anticancer, cardiovascular, and anti-inflammatory activity. J Agric Food Chem. 2008, 56:6185-6205.

2. Manthey JA, Grohmann K, Guthrie N: Biological properties of citrus flavonoids

3. pertaining to cancer and inflammation. Curr. Med. Chem. 2001, 8:135-153.

4. Manthey JA, Grohmann K: Concentration of hesperidin and other orange peel

5. flavonoids in citrus processing byproducts. J Agric Food Chem 1996, 44:811-814.

6. Mandalari G, Bennett RN, Bisignano G, Trombetta D, Saija A, Faulds CB, Gasson MJ, Narbad A: Antimicrobial activity of flavonoids extracted from bergamot (Citrus bergamia Risso) peel, a byproduct of the essential oil industry. J Appl Microbiol 2007, 103:2056-2064.

7. Lin Y, Bai L, Chen W, Xu S: The NF-kappaB activation pathways, emerging molecular targets for cancer prevention and therapy. Expert Opin Ther Targets 2010, $14: 45-55$.

8. Van Waes C: Nuclear factor-kappaB in development, prevention, and therapy of cancer. Clin Cancer Res. 2007, 13:1076-82.

9. Lai CS, Li S, Liu CB, Miyauchi Y, Suzawa M, Ho CT, Pan MH: Effective suppression of azoxymethane-induced aberrant crypt foci formation in mice with citrus peel flavonoids. Mol Nutr Food Res 2013, 57:551-555.

10. Pan MH, Li S, Lai CS, Miyauchi Y, Suzawa M, Ho CT: Inhibition of citrus flavonoids on 12-O-tetradecanoylphorbol 13-acetate-induced skin inflammation and tumorigenesis in mice. Food Science Human Wellness 2012, 1:65-73.

11. Ignarro LJ: Nitric oxide as a unique signaling molecule in the vascular system: a historical overview. J Physiol Pharmacol 2002, 53: 503-514.

12. Ignarro LJ: Nitric oxide. Curr Top Med Chem. 2005, 5:595.

13. Sugiura $H$, Ichinose $M$ : Nitrative stress in inflammatory lung diseases. Nitric Oxide. 2011, 25:138-144.

14. Kanwar JR, Kanwar RK, Burrow H, Baratchi S: Recent advances on the roles of NO in cancer and chronic inflammatory disorders. Curr Med Chem. 2009, 16:2373-2394.

15. Janakiram NB, Rao CV: iNOS-selective inhibitors for cancer prevention: promise and progress. Future Med Chem. 2012, 4:2193-2204. 
16. Morgan MJ, Liu ZG: Crosstalk of reactive oxygen species and NF- $\kappa \mathrm{B}$ signaling.

17. Cell Res. 2011, 21:103-115.

18. Gloire G, Legrand-Poels S, Piette J: NF-kappaB activation by reactive oxygen species: fifteen years later. Biochem Pharmacol. 2006, 72:1493-1505.

19. Wang T, Zhang X, Li JJ: The role of NF-kappaB in the regulation of cell stress responses. Int Immunopharmacol. 2002, 2:1509-1520.

20. Häcker H, Karin M: Regulation and function of IKK and IKK-related kinases. Sci STKE. 2006, 357: re13.

21. Jomova K, Valko M: Advances in metal-induced oxidative stress and human disease. Toxicology. 2011, 283:65-87.

22. Lonkar P, Dedon PC: Reactive species and DNA damage in chronic inflammation: reconciling chemical mechanisms and biological fates. Int J Cancer. 2011, 128:1999-2009. 